\title{
Quinolone derivative, flumequine, as short-term treatment for gonorrhoea
}

\author{
H B SVINDLAND, P L SVARVA, AND J A MAELAND \\ From the Department of Dermatology and Microbiology, University Hospital, Trondheim, Norway
}

SUMMARY The antigonococcal activity of the quinolone derivative flumequine was evaluated. Of 246 strains examined, $240(97 \cdot 5 \%)$ strains showed minimum inhibitory concentrations (MICs) of flumequine of $\leqslant 0.4 \mu \mathrm{g} / \mathrm{ml}$, including three $\beta$-lactamase-producing strains. The six remaining strains showed MICs from 3.2 to $9 \cdot 6 \mu \mathrm{g} / \mathrm{ml}$. By disc diffusion tests using 3- $\mu \mathrm{g}$ discs of flumequine the zones of growth inhibition correlated well with the MICs of flumequine.

The effect of treatment with flumequine was compared in 239 patients with uncomplicated gonorrhoea. A single-dose regimen of $1200 \mathrm{mg}$ flumequine orally, a two-dose regimen of 1200 and $800 \mathrm{mg}$, and a three-dose regimen of 1200,800 , and $800 \mathrm{mg}$ (six hours apart) were given. With a single dose of flumequine the failure rate was $26 \%$. The two-dose and three-dose regimens were equally effective with an overall cure rate of $95.4 \%$. In patients harbouring $\beta$-lactamaseproducing gonococci the infection was cured. The failures $(10 \mathrm{men})$ included all of the six patients infected with flumequine-resistant gonococci. Side effects were noted by $14 \cdot 6 \%$ of the patients and were mostly described as dizziness.

\section{Introduction}

Flumequine is a synthetic antibacterial agent for oral use. It is a quinolone derivative and is thus structurally related to nalidixic acid, oxolonic acid, and rosoxacin. Like these drugs its antibacterial activity, which is bactericidal, is mostly directed against Gram-negative bacteria. Flumequine is well absorbed after oral administration which results in therapeutic concentrations in serum, tissues, and body fluids including urine. This drug has been used for the treatment of urinary tract infections (Riker Laboratories Ltd, unpublished data).

Gonorrhoea which is resistant to treatment with penicillins occurs with variable frequency in different parts of the world. Thus, $28 \cdot 8 \%$ of gonococci isolated in Singapore in 1980 were resistant due to production of $\beta$-lactamase.' Penicillin-resistant gonococci frequently show reduced susceptibility to a number of other antimicrobial agents. ${ }^{23}$ Gonococci producing $\beta$-lactamase have been reported to be resistant to spectinomycin. ${ }^{4}$ This emphasises the importance of evaluating alternatives to the antimicrobial agents currently used for the treatment of gonorrhoea. The quinolone derivatives represent

Address for reprints: Dr $\mathrm{H}$ B Svindland, Department of Dermatology, Regional Hospital, N-7000 Trondheim, Norway

Accepted for publication 28 May 1982 potential alternative drugs since earlier observations have shown that most gonococcal strains are susceptible in vitro to such agents, ${ }^{5-7}$ and that flumequine, as evaluated in the present study, attains therapeutic concentrations in the human body.

\section{Patients and methods}

Volunteers for enrolment into the study were women and men over 16 years of age attending the outpatient clinic for venereal diseases at the University Hospital, Trondheim, during 1981. All the patients had uncomplicated gonorrhoea, verified by examination of smears and by culture. Pregnant women were excluded from the study.

\section{DIAGNOSIS}

Gram-stained smears of material from the urethra of male patients and from the urethra and cervix of female patients were examined. Specimens for culture of gonococci were taken from the urethra of men and the urethra, cervix, and rectum of women using charcoal-impregnated swabs and Stuart's transport medium. Occasionally specimens for culture were taken from the oropharynx or from the rectum of homosexual men. The specimens were plated the same day on a modified New York City medium. ${ }^{8}$ The plates were incubated in candle jars at 
$37^{\circ} \mathrm{C}$ and were inspected after 24 and 48 hours. Gonococci were identified by colonial morphology, oxidase activity, Gram-staining, sugar fermentation, and some of the strains by immunofluorescence or coagglutination testing (Phadebact, Pharmacia, Uppsala, Sweden).

\section{SUSCEPTIBILITY TESTING}

Chocolate agar (Gc agar base, $1 \%$ supplement VX, $1 \%$ haemoglobin; Difco) was used for determining the minimum inhibitory concentrations (MICs) of flumequine and for disc diffusion testing. For the determination of MICs two-fold dilutions of flumequine from 0.05 to $9.6 \mu \mathrm{g} / \mathrm{ml}$ were incorporated into the agar medium. Gonococci were suspended in sterile $0.9 \%$ saline to a viable count of approximately $10^{6} / \mathrm{ml}$. The plates were seeded from the suspension by means of a calibrated loop obtaining semiconfluent colonies on plates without the antimicrobial agent. The plates were incubated in candle jars at $37^{\circ} \mathrm{C}$ for 48 hours. The MIC was defined as the least concentration of flumequine which inhibited growth of the bacteria.

For disc diffusion testing chocolate agar plates were flooded with the bacterial suspension to give semiconfluent growth. The plates were air-dried, and paper discs (Oxoid, England) impregnated with $3 \mu \mathrm{g}$ of flumequine were applied. The diameter of the zone of inhibition was measured after incubation in a candle jar at $37^{\circ} \mathrm{C}$ for 48 hours.

\section{TREATMENT WITH FLUMEQUINE}

The patients were assigned to three groups according to three dosage regimens: (A): flumequine 1200,800 , and $800 \mathrm{mg}$ (three doses) orally at six hourly intervals; (B): flumequine 1200 and $800 \mathrm{mg}$ (two doses) at six hourly intervals; and (C): flumequine in a single dose of $1200 \mathrm{mg}$.

\section{FOLLOW-UP EXAMINATION}

The patients were examined by microscopy of smears and by culture at one and two weeks respectively after treatment. At the follow-up examination the patients were asked for any possible side effects.

\section{Results}

IN-VITRO SENSITIVITY TESTS

All of the $\mathbf{2 4 6}$ primary gonococcal isolates from the patients under study were examined for their MICs of flumequine and 172 of the strains by the disc diffusion method. MICs of flumequine ranged from 0.05 to $9.6 \mu \mathrm{g} / \mathrm{ml}$ with a mean value of $0.16 \mu \mathrm{g} / \mathrm{ml}$ (table I). The strains showed a bimodal distribution for MICs. MICs of $\leqslant 0.4 \mu \mathrm{g} / \mathrm{ml}$ were recorded for $97.6 \%$ of the isolates with a peak number of strains at $0.1 \mu \mathrm{g} / \mathrm{ml} ; 2 \cdot 4 \%$ of the strains had MICs of $\geqslant 3 \cdot 2 \mu \mathrm{g} / \mathrm{ml}$.

The correlation between flumequine MICs and the diameter of the inhibition zones measured on disc diffusion testing of the gonococci is shown in the figure. The inverse correlation was good $(r=-0 \cdot 885$, $\mathrm{P}<0.01$; least squares method). An MIC of $0.4 \mu \mathrm{g} / \mathrm{ml}$ was defined as the breakpoint between sensitive strains and those showing reduced sensitivity to flumequine, this value corresponded to an inhibition zone of $28 \mathrm{~mm}$ in diameter using discs containing $3 \mu \mathrm{g}$ of the drug.

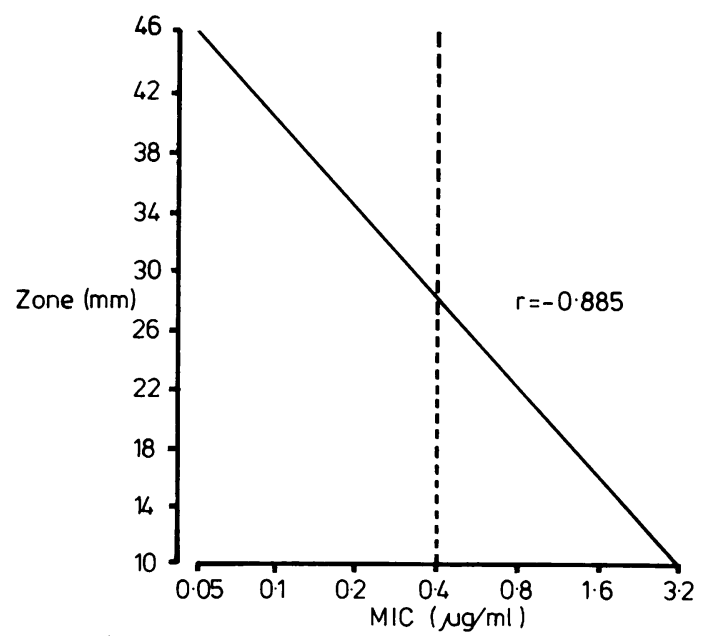

FIGURE Regression analysis of MICs of flumequine for gonococci and diameter of zones of growth inhibition

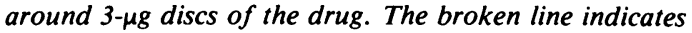
breakpoint between sensitivity and reduced sensitivity of gonococci for flumequine.

TABLE I Minimum inhibitory concentrations (MICs) of flumequine for 246 gonococcal strains isolated from patients before treatment

\begin{tabular}{llllllll}
\hline & \multicolumn{2}{l}{ MICs $(\mu \mathrm{g} / \mathrm{ml})$ of flumequine: } \\
\cline { 2 - 7 } Strains & 0.05 & $0 \cdot 1$ & $0 \cdot 2$ & $0 \cdot 4$ & $3 \cdot 2$ & $4 \cdot 8$ & $9 \cdot 6$ \\
\hline No $(\%)$ & $23(9 \cdot 3)$ & $166(67 \cdot 5)$ & $46(18 \cdot 7)$ & $5(2 \cdot 0)$ & $1(0 \cdot 4)$ & $3(1 \cdot 2)$ & $2(0 \cdot 8)$ \\
\hline
\end{tabular}


Growing gonococci showed well-defined demarcation towards the zone of growth inhibition. The strains examined included three which produced $\beta$-lactamase; these strains had MICs of flumequine of $0 \cdot 05,0 \cdot 1$, and $0 \cdot 2 \mu \mathrm{g} / \mathrm{ml}$ respectively.

\section{CLINICAL TRIAL}

A total of 246 patients with gonorrhoea received treatment with flumequine according to the dosage regimen A (100 patients), B (123 patients), or C (23 patients). Evaluation of the efficacy of the treatment was based on 239 of the patients ( 95 female and 144 male) who attended the follow-up examination.

Treatment according to regimen $\mathrm{C}$, a single oral dose of $1200 \mathrm{mg}$ flumequine, was given to 23 patients. Treatment failure was noted in six $(26 \%)$ of the patients, so regimen $\mathrm{C}$ was discontinued. All of the gonococcal isolates from these patients had MICs of $\leqslant 0 \cdot 4 \mu \mathrm{g} / \mathrm{ml}$ of flumequine.

The results of treatment obtained with regimen $A$ (three doses of flumequine) and with regimen B (two doses) are shown in table II. The two regimens were equally effective, both of them resulting in cure in all the female patients and in more than $90 \%$ of the male patients, an overall cure rate of $95 \cdot 4 \%$.

TABLE II Results obtained with regimens $A$ (three doses) and $B$ (two doses) of flumequine in patients with uncomplicated gonorrhoea

\begin{tabular}{|c|c|c|c|c|c|}
\hline \multirow{2}{*}{$\begin{array}{l}\text { Treatment } \\
\text { group }\end{array}$} & \multirow{2}{*}{$\begin{array}{l}\text { No of } \\
\text { patients }\end{array}$} & \multicolumn{2}{|c|}{ Cure } & \multicolumn{2}{|c|}{ Failure } \\
\hline & & $N o$ & $\%$ & No & $\%$ \\
\hline \multicolumn{6}{|l|}{ Regimen A: } \\
\hline Female & 41 & 41 & 100 & 0 & \\
\hline Male & 56 & 51 & $91 \cdot 1$ & 5 & $8 \cdot 9$ \\
\hline Total & 97 & 92 & $94 \cdot 8$ & 5 & $5 \cdot 2$ \\
\hline \multicolumn{6}{|l|}{ Regimen B: } \\
\hline Female & 46 & 46 & 100 & 0 & \\
\hline Male & 73 & 68 & $93 \cdot 2$ & 5 & $6 \cdot 8$ \\
\hline Total & 119 & 114 & $95 \cdot 8$ & 5 & $4 \cdot 2$ \\
\hline
\end{tabular}

The failures (10 male patients) included all of the six patients who were infected with strains of gonococci having flumequine MICs of $\geqslant 3 \cdot 2 \mu \mathrm{g} / \mathrm{ml}$. Flumequine-sensitive gonococci on primary culture and resistant strains at the first follow-up examination were recorded in two of the failures. Gonococci sensitive to flumequine were isolated from the remaining two failures, both before and after treatment.

\section{SIDE EFFECTS}

Side effects were noted by $14.6 \%$ of the patients (table III) $(22 \cdot 1 \%$ of the women and $9 \cdot 7 \%$ of the men). They were mostly vague in character, appeared shortly after the first dose of flumequine, lasted for 4-6 hours, and were described mostly as dizziness and
TABLE III Side effects noted by patients with gonorrhoea receiving treatment with three doses of flumequine $(A)$, two doses $(B)$, and a single dose $(C)$ respectively

\begin{tabular}{lllll}
\hline \multirow{2}{*}{$\begin{array}{l}\text { Treatment } \\
\text { regimen }\end{array}$} & Sex & $\begin{array}{l}\text { No of } \\
\text { patients }\end{array}$ & \multicolumn{2}{c}{ Side effects } \\
\cline { 4 - 5 } & Fo & No & \\
\hline A & M & 41 & 15 & $36 \cdot 6$ \\
& F & 56 & 7 & $12 \cdot 5$ \\
B & M & 76 & 5 & $10 \cdot 9$ \\
C & F & 8 & 6 & $8 \cdot 2$ \\
& M & 15 & 1 & $12 \cdot 5$ \\
& & & 1 & $6 \cdot 7$ \\
\hline
\end{tabular}

in a few patients as confusion. The side effects did not prevent patients completing treatment except for one woman who had minor neurological disturbances.

\section{Discussion}

The present study has shown that $\mathbf{9 7 \cdot 6 \%}$ of gonococci isolated from patients in our community before treatment of the infection were sensitive to flumequine. The MICs of flumequine for gonococci showed a bimodal distribution similar to that observed for MICs of $\beta$-lactam antibiotics. ${ }^{9}$ This is different from MICs for gonococci of rosoxacin, which is another quinolone derivative. ${ }^{6}$ Thus a few $(2 \cdot 4 \%)$ of the strains isolated from the patients studied showed primary high-level resistance to flumequine. The frequency of strains showing primary resistance to flumequine may vary from one geographical area to another, affecting accordingly the usefulness of this drug for the treatment of gonorrhoea. The genetic basis for flumequine resistance in gonococci has not been studied. In-vitro studies with Proteus vulgaris, however, have shown that environmental pressure by flumequine resulted in the selection of mutants relatively resistant to this drug (Riker Laboratories Ltd., unpublished data). Gonococcal strains showing primary resistance to flumequine may have emerged as a result of selective pressure in individuals with gonorrhoea who have received subtherapeutic concentrations of a quinolone derivative. Thus, in two of the patients in the present study treatment failure may have resulted from selection of resistant mutants of the gonococcus. The potential risk of selecting resistant mutants during treatment with flumequine requires further elucidation.

Gonococci with reduced sensitivity to penicillins frequently show reduced susceptibility to a number of other antimicrobial agents. ${ }^{23}$ In the present study MICs of flumequine were not correlated with those of other antibiotics. All the patients infected with flumequine-resistant gonococci were, however, cured 
by treatment with pivampicillin. All three gonococcal isolates producing $\beta$-lactamase were susceptible to flumequine and the patients infected with these bacteria were cured with this drug.

The efficacy of antimicrobial agents in the treatment of gonorrhoea is obviously related to the MICs for the infecting strains. ${ }^{10}$ Clearly, this was also the case with flumequine. The dosage regimens $\mathrm{A}$ and $\mathrm{B}$ resulted in an overall cure rate of $98 \%$ of the patients infected with gonococci with MICs $\leqslant 0.4 \mu \mathrm{g} / \mathrm{ml}$. None of the patients with gonococci with MICs $\geqslant 3.3 \mu \mathrm{g} / \mathrm{ml}$ were cured. The two-dose regimen of flumequine was fully effective whereas the singledose regimen was not. Thus, eradication of gonococci requires therapeutic serum concentrations of flumequine for several hours. The two-dose regimen resulted in the cure of patients with rectal gonorrhoea, including one homosexual man. All of the failures were male patients. The reason for this has not been fully explained. The primary isolates showing flumequine resistance may, however, have originated from the same two infection sources. Prolonged treatment of these patients, even with higher doses of flumequine, did not result in cure.

Side effects of flumequine were noted by $14 \cdot 6 \%$ of the patients, mostly women. The side effects resembled those observed with nalidixic acid ${ }^{11}$ and rosoxacin $^{12}$ and suggest neurotoxicity. Severe side effects, however, were noted in only one patient. Nevertheless, the effects observed warrant advice against certain activities, such as car driving, for at least six hours after the first dose. Studies not yet completed have shown that the occurrence of adverse reactions can be reduced by adjusting the dosage according to body weight without reducing the efficacy of the drug in the treatment of gonorrhoea.

Facilities for the culture of Chlamydia trachomatis were available only for the last month of the study. During this time five of the male patients developed postgonococcal urethritis after cure for gonorrhoea by treatment with flumequine. Chlamydia was isolated from the urethra of all of these patients. All of these patients received the two-dose regimen and the results are in contrast to those observed clinically in patients receiving the three-dose regimen, in whom no cases of post-gonococcal urethritis occurred.
This study has shown that shoit-term treatment $\stackrel{\Xi}{\overparen{D}}$ with flumequine was highly effective in treating uncomplicated gonorrhoea. The efficacy of this drug in the treatment of complications of gonorrhoea or $\vec{z}$ infections caused by bacteria other than Neisseria gonorrhoeae requires further investigation.

We are grateful to Riker Laboratories Ltd for making this study possible. We thank Mrs Randi Bjфrgen and Mrs Àse Gerd Vist for excellent technical assistance.

\section{References}

1. Anonymous. Wkly Epidem Rec 1981;56:189-90.

2. Reynolds GH, Zaidi AA, Thornsbury C, Guinon M, Biddle J, Wiesner PJ. The national gonorrhea therapy monitoring study. II Trends and seasonality of antibiotic resistance of Neisseria gonorrhoeae. Sex Transm Dis 1979;6 suppl 2:103-11.

3. Sparling PF. Antibiotic resistance in the gonococcus. In: Roberts RB, ed. The Gonococcus. New York, Chichester, O Brisbane, Toronto: John Wiley \& Sons, 1977:111-35.

4. Anonymous. Wkly Epidem Rec 1981;56:158.

5. Dobson RA, O'Connor JR, Poulin SA, Kundsin RB, Smith TF, Came PE. In-vitro antimicrobial activity of rosoxacin against Neisseria gonorrhoeae, Chlamydia trachomatis, and Ureaplasma urealyticum. Antimicrob Agents Chemother 1980; 18: $738-40$.

6. Seth AD. Sensitivity of gonococci to rosoxacin compared with that of penicillin, cefuroxime, and tetracycline. $J$ Antimicrob Chemother 1981;7:331-4.

7. Warren CA, Shannon KP, Phillips I. In-vitro antigonococcal activity of rosoxacin (WIN 35213). Br J Vener Dis 1981;57: 33-5.

8. Svarva PL, Maeland JA. Comparison of two selective media in the cultural diagnosis of gonorrhoea. Acta Pathol Microbiol Scand B 1979;87:391-2.

9. Gordts B, Vanhoof R, Hubrechts JM, Dierick R, Coignoe H, Butzler JP. In-vitro activity of 21 antimicrobial agents against Neisseria gonorrhoeae in Brussels. Br J Vener Dis 1982;58: 23-8.

10. Percival A, Hart CA. Rationale for antimicrobial therapy of infections caused by multiple resistant Neisseria gonorrhoeae. In: Brooks CF, Gotschlich EC, Holmes KK, Sawyer WD, Young FE, eds. Immunobiology of Neisseria gonorrhoeae. Washington DC: American Society for Microbiology, 1978: 79-85.

11. Kucers A, Bennett NM. The Use of Antibiotics. A compre hensive Review with Clinical Emphasis. 3rd ed. London: William Heinemann Medical Books Ltd, 1979.

12. Limson BM, Macasaet RK, Salem JJ, Beling CG, Burnham HA. Double-blind dose-ranging, efficacy and tolerance study of rosoxacin (Eradacil) in male gonorrhoea. Curr Ther Res 1979; 26: 842-7. 